\title{
Alkaloids in Australian rye ergot (Claviceps purpurea) sclerotia: implications for food and stockfeed regulations
}

\author{
Barry J. Blaney ${ }^{\mathrm{A}, \mathrm{B}}$, John B. Molloy ${ }^{\mathrm{A}}$ and lan J. Brock ${ }^{\mathrm{A}}$ \\ APrimary Industries and Fisheries, LMB 4, Moorooka, Qld 4105, Australia. \\ ${ }^{\mathrm{B} C}$ Corresponding author. Email: barry.blaney@dpi.qld.gov.au
}

\begin{abstract}
Rye ergot (Claviceps purpurea) occasionally causes toxicity (chiefly expressed as hyperthermia) in Australian livestock, either as a result of grazing infected annual (Lolium rigidum) and perennial (L. perenne) rye grasses, or if the ergot sclerotia produced in rye grasses contaminate grain crops used as stockfood. Alkaloids in 30 samples of Australian rye ergot sclerotia taken from rye grasses and grain screenings, and some feed samples contaminated with rye grass ergot sclerotia, were assayed by high performance liquid chromatography. Samples originated from across southern Australia. Ergotamine was the dominant alkaloid in all samples, followed by $\alpha$-ergocryptine, ergocornine, ergosine and their respective -imine epimers. Ergotamine concentrations in sclerotia ranged up to $2257 \mathrm{mg} / \mathrm{kg}$ (as received basis). Ergocristine was a very minor component $(<50 \mathrm{mg} / \mathrm{kg})$ in all samples. Total alkaloids in freshly collected sclerotia ranged from 1003 to $3321 \mathrm{mg} / \mathrm{kg}$ ( 0.10 to $0.33 \%$ ), and up to $3766 \mathrm{mg} / \mathrm{kg}$ with epimers included, although lower concentrations were found in samples stored for some time. Alkaloid profiles in sclerotia were all very similar, and concentrations did not appear to be related to size of sclerotia, source region, nor to the rye grass or grain from which they were taken. Previous cases of toxicity in livestock are reviewed and several new cases are reported. The implications of variable alkaloid contents of rye ergot sclerotia are discussed in terms of Australian food and stockfeed regulations.
\end{abstract}

Additional keywords: fungus, mycotoxin.

\section{Introduction}

Rye ergot (Claviceps purpurea Fr. Tul.) is a fungus that infects annual (Lolium rigidum Gaudin) and perennial (L. perenne L.) rye grasses across southern Australia. Infection of cereal crops, especially rye but also wheat, barley and triticale, occurs in Europe and North America (Scott et al. 1992; EFSA 2005) but is rare in Australia, apparently due to the dry conditions prevailing during flowering of these crops. Poisoning of livestock occurs only occasionally and in a few localities, usually as a result of grazing infected rye grass (Jessep et al. 1987). However, it also occurs from feeding contaminated grain to livestock, if rye grass is not controlled in winter cereal crops, which are then contaminated by ergot sclerotia produced in the rye grass (Peet et al. 1991; Bourke 2000). Rye grass ergot sclerotia in grain traded by bulk handlers are limited by industry trading standards and some state government regulations, but toxicity problems can result from direct sales from farm to farm. Contamination of grain intended for human consumption is very uncommon in Australia, but Food Standards Australia New Zealand (previously the Australia and New Zealand Food Authority) has set a maximum of $500 \mathrm{mg} / \mathrm{kg}$ $(0.05 \% \mathrm{w} / \mathrm{w})$ in the Food Standards Code for ergot in cereal grain (ANZFA 2000).

Rye ergot can produce a range of alkaloids, including ergonovine (ergometrine), ergosine, ergotamine, ergocornine, ergocryptine and ergocristine but the alkaloid profile and content of rye ergot sclerotia produced in different grains and from different countries can vary considerably (Young and Chen 1982) which can affect toxicity (Dignean et al. 1986). Other variables include the instability of alkaloids in feed and their potential for conversion to isomers $\left(\mathrm{C}_{8}\right.$ epimers $)$ which are relatively inactive in laboratory animal models used for development of human pharmaceuticals (Stoll 1952; Berde and Stürmer 1978) and have therefore been discounted in previous livestock toxicity studies. There is little information published on the alkaloid composition of Australian rye grass ergot sclerotia, and in an official review of maximum ergot concentrations permitted in food in Australia, only data from North America, Europe and south-east Asia were quoted (ANZFA 1999).

Ergot alkaloids reduce circulating prolactin concentrations, with severe impact on milk production of sows (Kopinski et al. 2007). They also have vasopressor effects, reducing peripheral blood circulation and interfering with heat regulation in ruminants. This leads to hyperthermia particularly in warm conditions, or gangrene of extremities particularly in cool conditions, severely reducing feed intake and growth rates (Schneider et al. 1996). The tolerance of livestock to specific rye ergot alkaloids is not clear, partly because few studies have recorded the alkaloid content of the feed.

Consequently, we report here the alkaloid composition of samples of Australian rye grass ergot sclerotia, relate these toxin concentrations to cases of livestock poisoning in Australia, and review the implications for regulating safe levels of sclerotia in grain and feed. 


\section{Materials and methods}

\section{Source of samples and case histories}

Grain and grain screenings contaminated with rye grass ergot (referred to subsequently as diagnostic samples) were obtained from feed companies and livestock producers - in some cases connected with hyperthermia in livestock, and in others to gauge suitability for feeding. Details of the source and reasons for submission are in Table 1. A few sclerotia from these samples were assayed separately. Four larger samples of sclerotia (follow-up samples) were obtained from collaborators across southern Australia as per Table 2. Three had been collected in 1998-2001 and one in 2006-07 and all had been stored at room temperature for 1-2 years. After receipt in the laboratory they were stored at $-20^{\circ} \mathrm{C}$ for another $1-3$ years before assay. Attempts to source additional samples during 2004-07 were largely unsuccessful. However, late in 2008 there were widespread problems with rye grass ergot along the south coast of Western Australia involving rejection of grain by bulk handlers (J. Allen, pers. comm.) and another 24 samples of sclerotia were collected from individual farmers crops, from grain deliveries rejected by bulk handlers, and from screenings from grain cleaning companies. These samples came from crops grown across the southern regions of Western Australia as indicated in Table 3. In addition, one sample was taken directly from perennial rye grass at Waroona and another from infected pasture at Ravensthorpe. These 26 samples are referred to as 2008 samples (Table 3). The weights of sclerotia submitted, or removed from grain samples submitted, ranged from $0.2-3 \mathrm{~g}$. An approximate estimate of the size of sclerotia was recorded (average length, range).

\section{Alkaloid standards}

Ergotamine, ergocornine, $\alpha$-ergocryptine, ergocristine and ergonovine were purchased as either tartrate or methanesulfonate derivatives (Sigma-Aldrich, St Louis, MO, USA). However, all results are quoted in terms of the base alkaloids. Standards were stored at $-20^{\circ} \mathrm{C}$ in the dark. Standard solutions were prepared in $70 \%$ methanol, stored refrigerated in the dark, and used within a few days of preparation to minimise epimerisation.

\section{Analytical methods}

Grain samples were assayed for alkaloids by HPLC using a method based on that of Scott and Lawrence (1980). The HPLC system used a Novapac (Waters) C18 column 150 by $3.9 \mathrm{~mm}$, operated isocratically at $40^{\circ} \mathrm{C}$. The mobile phase was acetonitrile : methanol : $0.1 \%$ ammonium acetate $(30: 20: 50)$ at a flow rate of $1 \mathrm{~mL} / \mathrm{min}$. Detection was both by fluorescence (excitation $235 \mathrm{~nm}$, emission $370 \mathrm{~nm}$ ) and by UV absorption (240 nm). UV spectra were obtained by using a photodiode array detector (in the range 190 to $370 \mathrm{~nm}$ ) for standard alkaloids and for all peaks in sample chromatograms. Absorption maxima $(206,238,312 \mathrm{~nm})$ and their ratios were used for additional confirmation of identity.

Only ergotamine was available as a standard at the time of assay of the diagnostic grain samples, so other alkaloids were presumptively identified by comparison to relative retention times in published chromatograms (Scott and Lawrence 1980) and similar spectral profiles. Estimates of total alkaloids were made based on peak areas relative to ergotamine, and epimers were not assayed. Three of the samples were large enough to be split and allow a few sclerotia to be assayed separately (Table 1), but only one of these provided enough sclerotia to allow more accurate assay when additional standards were subsequently acquired. Mean recovery of ergotamine from grain samples was $68 \%$, but results quoted have not been corrected for these recoveries. The detection limits for ergotamine in grain samples ranged from $0.02-0.05 \mathrm{mg} / \mathrm{kg}$, depending on the sample matrix, and level of quantification was $0.1 \mathrm{mg} / \mathrm{kg}$.

Sclerotia $(0.1 \mathrm{~g})$ were extracted with two sequential aliquots of $20 \mathrm{~mL}$ methanol by grinding in a mortar and pestle (later samples were extracted in a high speed IKA Ultra-Turrax homogenizer), filtered, dried under vacuum (rotary evacuator), and reconstituted in $1 \mathrm{~mL}$ methanol before HPLC injection. Epimerisation of ergot alkaloids readily occurs in water-methanol solution at room temperature, with a half life of 2-5 days, but is much faster in acidic or alkaline buffers (Smith and Shappell 2002). Consequently, assays were performed over as short a period as possible $(2-4 \mathrm{~h})$. Ergonovine, ergotamine, ergocornine, $\alpha$-ergocryptine and ergocristine were all identified and quantified by reference to the pure compounds. Ergosine and all epimers (ergosinine, ergotaminine, ergocryptinine, ergocorninine) were identified from their UV spectral characteristics (practically identical to the parent alkaloids), and by conversion of pure standards to the respective epimers over time. Ergosine was quantified by peak area comparison with ergotamine. Epimers were quantified from peak areas in relation to parent alkaloids, assuming that molar absorptivities of isomers were identical, as indicated by Smith and Shappell (2002). Where possible, assays were performed in duplicate on separate days, and results were averaged.

\section{Results}

Ergotamine appeared to be the dominant alkaloid in diagnostic samples (Table 1), although other standards were not available at the time of assay, and this was supported by the results obtained in a few sclerotia extracted from these samples.

Alkaloid compositions of four 'follow-up' samples of sclerotia which had been stored for several years in ambient conditions are given in Table 2. Fresh sclerotia samples collected late in 2008 and stored for only a few months are shown in Table 3.

Ergotamine was the major alkaloid in all samples, followed by $\alpha$-ergocryptine. Ergocornine and ergosine were also present in all samples, but ergocristine and ergonovine were present in lower levels and only in some samples. The epimers of the various alkaloids were also present in substantial concentrations, even when injected into the HPLC within 15 min of extraction, so these are clearly present in sclerotia. Sclerotia stored for several years did not have markedly lower alkaloid contents than those stored for a few months, although the proportion of 'inactive' epimers appeared to be greater on average (36\% compared with $20 \%$ ). Sclerotia from diagnostic samples had lower total alkaloid contents $(200-500 \mathrm{mg} / \mathrm{kg})$ but epimers were not included in these assays and length of storage and storage conditions were unknown.

In 15 larger samples of sclerotia, the length and weight ratios were calculated, and the total length of $1 \mathrm{~g}$ of sclerotia averaged $86 \mathrm{~cm}$ (range 63-117). 

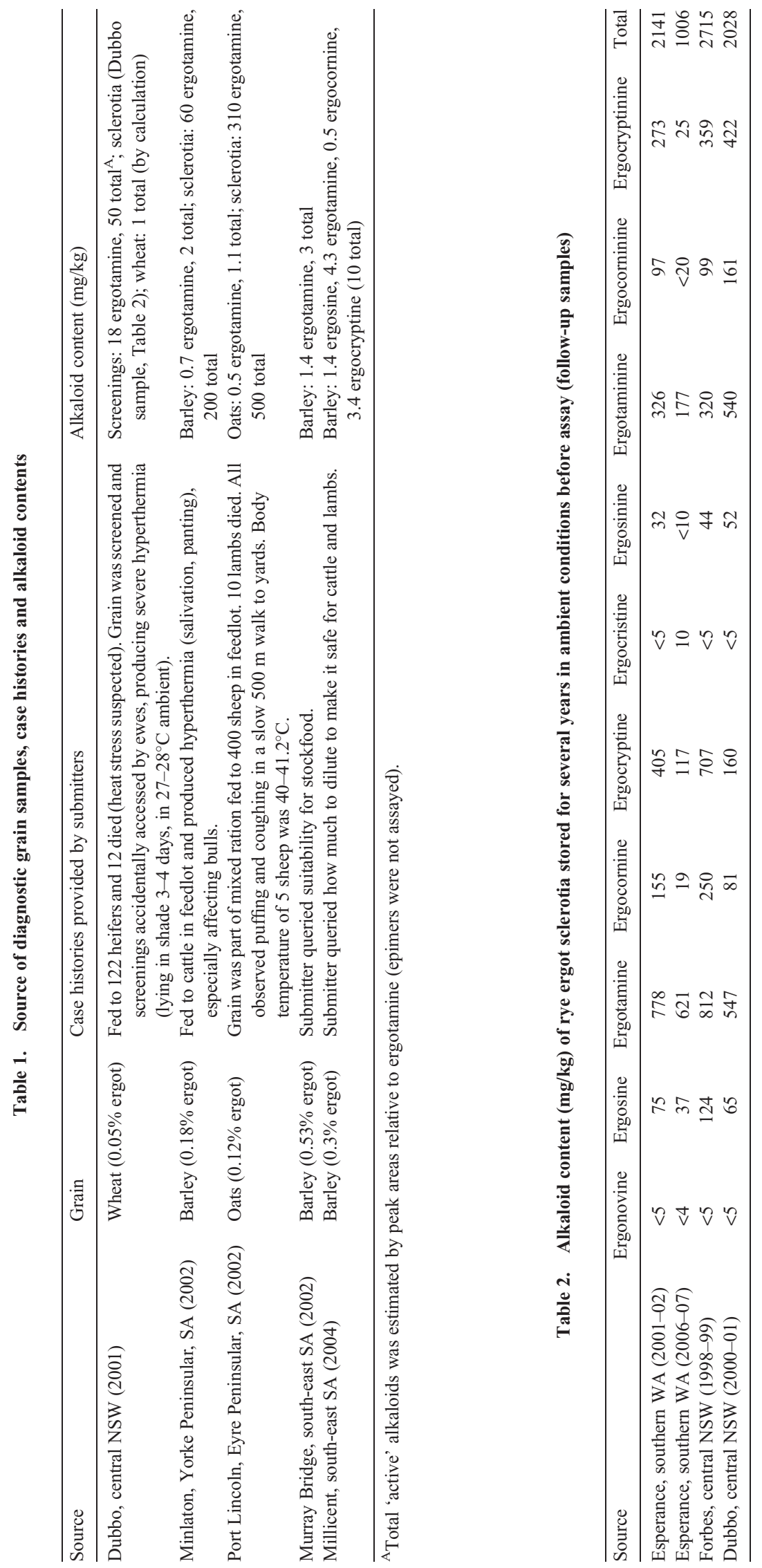


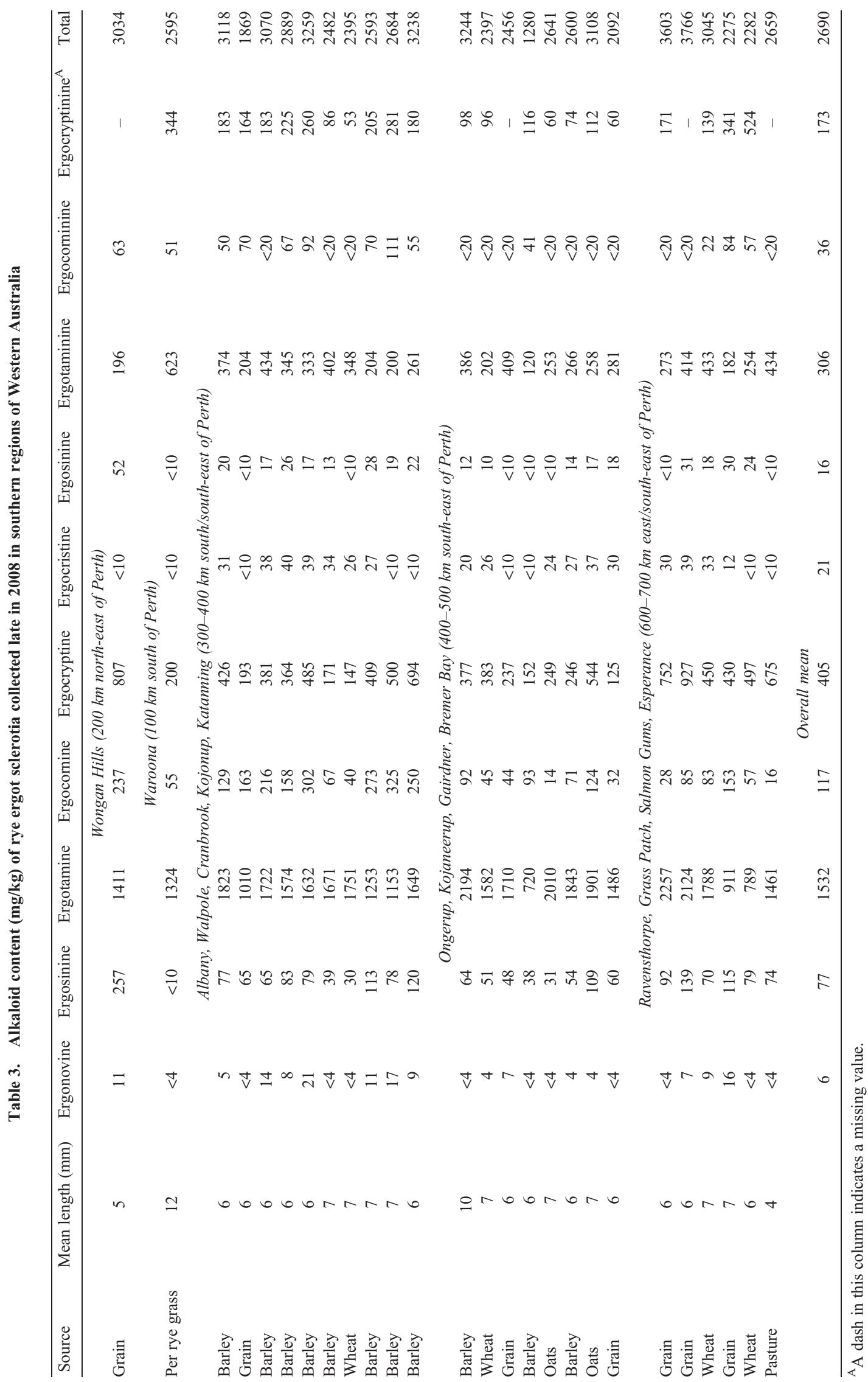


Alkaloid content (w/w) did not appear to be affected by size (length) of sclerotia. The mean alkaloid contents of sclerotia in relation to the mean length of sclerotia in samples were as follows: $6 \mathrm{~mm}, 2585 \mathrm{mg} / \mathrm{kg}$ (13 samples); $7 \mathrm{~mm}, 2620 \mathrm{mg} / \mathrm{kg}$ (nine samples); $10 \mathrm{~mm}, 3168 \mathrm{mg} / \mathrm{kg}$ (one sample).

Alkaloid profiles and contents were little affected by source. One sclerotia sample from infected perennial rye grass and another from unidentified pasture had similar profile and content as samples from grain screenings, mostly presumed to have originated from annual rye grass, but possibly from a mixture of rye grass sources. Alkaloid contents of sclerotia were not affected by the grain crop from which they were taken, when this could be identified: barley, $2613 \mathrm{mg} / \mathrm{kg}$ (10 samples); wheat, $2608 \mathrm{mg} / \mathrm{kg}$ (four samples); oats, $2796 \mathrm{mg} / \mathrm{kg}$ (two samples).

A chromatogram of a sclerotia sample collected in 2001-02 from Esperance in Western Australia is shown in Fig. 1. Alkaloid standards were all well resolved in the HPLC system, with typical retention times ( $\mathrm{min})$ as follows: ergonovine, 1.4; ergotamine, 5.3; ergocornine, 7.2; $\alpha$-ergocryptine, 9.8; ergocristine, 10.8. Similar chromatograms were obtained for other sclerotia samples. There was one peak between ergocryptine and ergocristine with a retention time of $10.3 \mathrm{~min}$ that had very similar UV spectral characteristics to the other alkaloids present and could have been $\beta$-ergocryptine (Müller et al. 2006).

\section{Discussion}

\section{Alkaloid profiles and contents}

The alkaloid profiles of rye grass ergot sclerotia from across southern Australia were similar. Ergotamine was always the main component, $\alpha$-ergocryptine was next abundant, with lesser concentrations of ergocornine and ergosine. Most sclerotia had total alkaloid contents ranging from $\sim 1000-3000 \mathrm{mg} / \mathrm{kg}$ $(0.1-0.3 \%)$, although a few sclerotia stored for long periods contained lower concentrations. This variation might derive from the proportion of sphacelial $v$. sclerotial tissues as occurs in sorghum ergot (Blaney et al. 2003, 2006) as sphacelial tissues produce comparatively little alkaloids.

The absence of significant amounts of ergocristine is of note, and apparently at variance with some reports in other countries. Whittemore and Miller (1977) found that sclerotia from $C$. purpurea-infected wheat from England contained predominantly ergocristine, ergocornine and $\alpha$-ergocryptine, with $<10 \%$ ergotamine. Frach and Blaschke (1998) found that several samples of rye (grain) ergot sclerotia from Germany contained mainly ergocryptine, ergocristine, ergonovine and ergocornine, with ergotamine representing less than $10 \%$ of the active alkaloids present. However, Mainka et al. (2007) reported assays on two batches of ergot from German rye grain, one of which contained ergotamine (41\% of active alkaloids), with ergosine and ergocristine the other major components.

In Canada, Young and Chen (1982) found ergocristine, ergotamine and their epimers to be dominant in sclerotia produced by $C$. purpurea in rye, triticale, wheat and barley crops, but ergotamine only exceeded ergocristine in rye grain. This was reinforced by a survey of rye, wheat and triticale flour and cereals over 6 years in Canada by Scott et al. (1992), where ergocristine also dominated over ergotamine and ergocornine. C. purpurea also infects tall fescue grass (Festuca arundinacea) in the USA, and Porter et al. (1987) found ergotamine, ergocristine and ergosine to be the main alkaloids produced in these sclerotia.

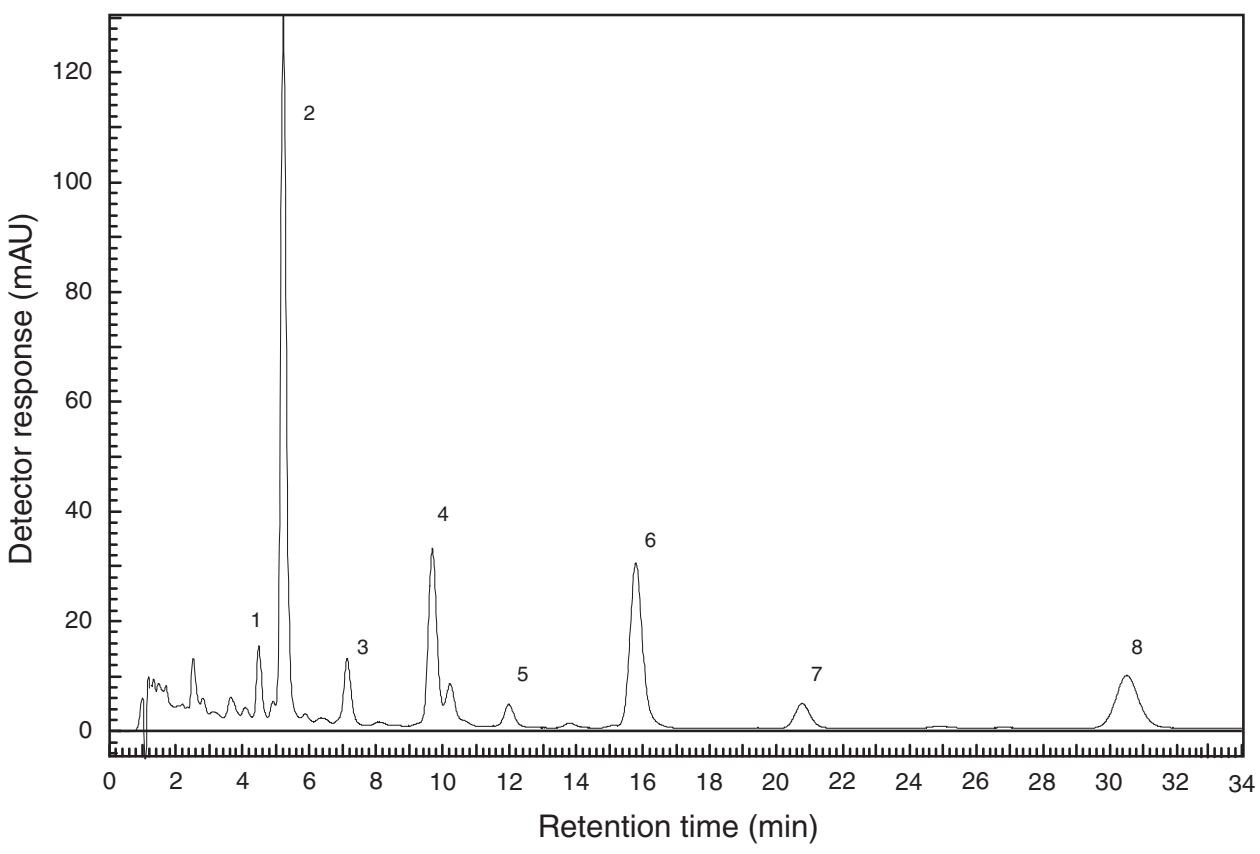

Fig. 1. High performance liquid chromatogram of an extract of rye ergot sclerotia from Esperance (2001-02 sample, Table 2) with components: ergosine (1); ergotamine (2); ergocornine (3); $\alpha$-ergocryptine (4); ergosinine (5); ergotaminine (6); ergocorninine (7); ergocryptinine (8). Ergonovine and ergocristine were not detected in this sample (retention time of standards was $1.8 \mathrm{~min}$ and $10.8 \mathrm{~min}$, respectively). 
In South Africa, Schneider et al. (1996) reported ergotamine and ergosine in one sample of rye grass ergot sclerotia and roughly equal concentrations of ergosine, ergotamine, ergocornine and ergocryptine in another. From these publications and our results, there appears to be a trend for ergotamine and ergocryptine to be more prevalent in ergot produced in rye grain and rye grass, and for ergocristine to be higher in ergot produced in wheat and triticale. All considered, the dominance of ergotamine and ergocryptine, and absence of significant amounts of ergocristine in our sclerotia is most likely due to host factors or to the C. purpurea genotype. During pioneering research on ergot, Stoll (1945) recognised two strains of ergot occurring in Europe, one yielding alkaloids of the ergotoxine group (ergocristine, ergocornine and ergocryptine) and the other yielding ergotamine and ergosine. He noted the former strain predominated in Spain and Russia, while both strains occurred in Hungary and Bulgaria.

The toxicological significance of these variations is not clear. Dignean et al. (1986) suggested that European ergot containing mainly ergocristine, ergocryptine and ergocornine was more toxic to pigs than ergot from western Canada containing predominantly ergocristine. Rotter et al. (1985) also found differences in toxicity to chickens between ergot produced in rye grain, wheat and triticale in Canada, but were unable to clarify the relationship between toxicity and alkaloid composition. There is currently little information about differences in toxicity towards ruminants. Browning and Leite-Browning (1997) showed that ergotamine (intravenous injection) reduced the heart rate of steers, whereas ergonovine did not: both increased blood pressure compared with controls. However, bioconversion of these different alkaloids in the rumen, possibly to common active intermediates, might negate the impact of different alkaloid profiles.

There are additional factors to consider in toxicity. A large proportion of the alkaloid content of sclerotia was represented by the various epimers. It is often unclear how much of the epimers are present in fresh sclerotia, and how much is a result of isomerisation during storage. The present results show relatively small changes in the proportions of epimers in samples stored for several years (Table 2) compared with a few months (Table 3 ), although the total alkaloid content of sclerotia stored for several years was somewhat lower. Because the epimers are far less active than the parent compounds in laboratory animal models, they are frequently ignored in analytical assessments of toxicity for livestock. However, they might have some impact in ruminants, as the epimers could be inter-converted with active isomers in the rumen. Another possibility is that both parent alkaloid and epimer are converted into compounds which have similar vasopressor activity.

Much research has been carried out on closely related ergot alkaloids produced by the fungal endophyte Neotyphodium coenophodium in tall fescue, mainly ergovaline and ergine. Stuedemann et al. (1998) and Hill et al. (2001) suggested that the alkaloids in tall fescue were biotransformed in the rumen before absorption as lysergic acid and other derivatives. They considered that the ergopeptide alkaloid ergovaline might not be the actual active agent in tall fescue toxicity in cattle, since transport of ergopeptide alkaloids across ruminal and abomasal tissues was less than that of the simpler alkaloids lysergic acid, lysergol and ergonovine, and there was an active transport process. These unknown factors suggest to us that the total alkaloid content of feed, including epimers, should be used as a measure of risk for ruminants.

\section{Cases of ergotism}

Hyperthermia in cattle from consuming grain contaminated with ergot sclerotia produced in perennial rye grass was reported in mid-NSW in 1987 (Jang et al. 1987; Jessep et al. 1987; Ross et al. 1989). The impact of ergot is more serious in lot-fed conditions, and serious mortalities occurred in several Western Australian feedlots in 1990 from feeding barley containing $0.06 \%$ rye grass ergot (Peet et al. 1991). Bourke (2000) reviewed more cases in central NSW in 1998 and 1999. Here we report further cases from central NSW and South Australia in 2001 and 2002, involving some mortalities.

The threshold tolerance of cattle and sheep for rye ergot alkaloids is not well defined. In three cases reported here, hyperthermia was apparently caused by feed containing 1-2 mg alkaloids/kg. In one controlled study, Bourke (2003) produced hyperthermia in cattle fed at the estimated equivalent of $1 \mathrm{mg}$ alkaloids/ $\mathrm{kg}$ in feed, based on preliminary assay results that we provided of $1200 \mathrm{mg}$ alkaloids $/ \mathrm{kg}$ in sclerotia. Our revised estimate of the alkaloid content of Bourke's sclerotia (Forbes sample, Table 2) is $1893 \mathrm{mg} / \mathrm{kg}$, or $2715 \mathrm{mg} / \mathrm{kg}$ if epimers are included. However, this does not affect the conclusions drawn by Bourke (2003), that sunlight exposure appears to be a critical factor in a particularly lethal form of hyperthermia in cattle and sheep, and that toxins other than ergot alkaloids could be involved, such as the ergochromes (Franck 1969; Buchta and Cvak 1999). Further research is required to investigate the ergochrome content of Australian rye ergot sclerotia and to clarify the role they play in toxicity to livestock.

There appear to be no reports in the Australian literature of rye ergot poisoning of pigs, which could be either because contamination is uncommon, or because piggeries purchase grain through bulk grain traders applying receival standards. However, poisoning of pigs by sorghum ergot (C. africana) has occurred (Blaney et al. 2000) - dihydroergosine, dihydroelymoclavine and festuclavine are the alkaloids responsible. Impaired lactation of sows and reduced feed intakes, rather than hyperthermia, are the main signs of poisoning both from rye ergot and sorghum ergot. One Australian study (Bakau et al. 1988) found reductions in growth rate and feed intake of pigs fed $0.75 \%$ rye ergot (alkaloid content not reported) which were exacerbated by higher temperatures $\left(35^{\circ} \mathrm{C}\right)$. The tolerances of pigs are not well defined, but a Canadian study (Oresanya et al. 2003) suggested maximum levels in feed of $0.1 \%$ rye ergot $(2 \mathrm{mg}$ alkaloid $/ \mathrm{kg}$ ) and $0.05 \%$ based on growth rates and feed intakes, respectively.

\section{Regulatory implications}

In a toxicological review and risk assessment for ergot levels in food (ANZFA 1999), it was proposed that the maximum permitted concentration for rye ergot in cereal grain in Australia and New Zealand be set at $500 \mathrm{mg} / \mathrm{kg}(0.05 \%)$, rather than the previous standard (in Australia) of "not 
detectable in $2.25 \mathrm{~L}$ sample of cereal grain'. No Australian assay data were available for review, and the assumed alkaloid content of ergot sclerotia was $0.1 \%(1000 \mathrm{mg} / \mathrm{kg})$. The Australia data presented here show substantially higher alkaloid contents, and an apparently different alkaloid profile than the North American and European data reviewed by ANZFA (1999), but the safety margins in the risk assessment appear adequate to account for these variations. While a limit of $0.05 \%$ ergot $(500 \mathrm{mg}$ ergot sclerotia $/ \mathrm{kg}$ ) remains a useful standard for Australian bulk grain, limits set on total ergot alkaloids should be considered for processed food, particularly imported products, where ergot sclerotia cannot be detected. There is an additional problem that alkaloids can sometimes still be detected in grain from which ergot sclerotia have been removed by screening, which is why alkaloid contents have been surveyed in human food in Canada (Scott et al. 1992) and pig feeds in Germany (Mainka et al. 2007).

Sorghum ergot has also poisoned cattle and pigs in Australia (Blaney et al. 2000, 2001), and is limited to $0.3 \%$ (3000 mg ergot sclerotia $/ \mathrm{kg}$ ) in grain for stockfood by Queensland Government regulation (Anon. 2003). Kopinski et al. (2008) recently considered the implications of the highly variable alkaloid contents of sorghum ergot sclerotia that could contaminate Australian stockfoods and recommended that regulations should be revised to include maximum alkaloid contents. The same issue of variable alkaloid contents is relevant to rye ergot, and perhaps Australian regulations should also specify alkaloid contents.

Bulk grain traders limit rye ergot sclerotia by length (laid end to end), for example the maximum limits set by Grain Trade Australia (2009) for 2009-10 for rye ergot sclerotia per half litre of grain were: wheat, $2 \mathrm{~cm}$; barley, $0.5 \mathrm{~cm}$; oats, $2 \mathrm{~cm}$; triticale, nil; rye, nil. Rye ergot sclerotia are restricted to $0.02 \%(\mathrm{w} / \mathrm{w})$ in grain under Queensland Stockfood Regulations (Anon. 2003) - a limit set many years ago on very limited toxicological data. The limit of $0.02 \%(200 \mathrm{mg}$ ergot $/ \mathrm{kg})$ is roughly equivalent to $8 \mathrm{~cm}$ rye ergot sclerotia per half litre of grain, based on the average weights and lengths of sclerotia assayed here.

In regard to livestock, sun-exposed ruminants are more sensitive to the effects of ergot than humans and other monogastric animals (ANZFA 1999). The few cases of livestock poisoning reviewed here, and the limited experiments reviewed, show severe hyperthermia in ruminants fed 1-2 mg ergot alkaloids/ $\mathrm{kg}$ of feed, suggesting that the total alkaloid content of feed should be restricted at least to $<0.5 \mathrm{mg} / \mathrm{kg}$. An extra safety margin is desirable to allow for irregular distribution of ergot sclerotia in bulk grain, and variations in individual susceptibility to ergot, so $<0.1 \mathrm{mg} / \mathrm{kg}$ appears a reasonable target. This equates to $\sim 0.004 \%$ rye ergot sclerotia $(40 \mathrm{mg} / \mathrm{kg}$ ) for sclerotia having an alkaloid content of around $2500 \mathrm{mg} / \mathrm{kg}$ (<2 cm sclerotia per half litre of grain). However, other risk factors include the unknown role of the ergot pigments in exacerbating hyperthermia in sunlight-exposed stock (Bourke 2003). All these variables combine to indicate that feed likely to contain any detectable rye ergot should be avoided for ruminant feedlot rations. Poultry and non-lactating mature (finisher) pigs present better options for use of lightly-contaminated grain than ruminants.

\section{Acknowledgements}

We greatly appreciate the assistance of Jeremy Allen, Chris Bourke and Steve Colegate in providing sclerotia samples, and Sally-Anne Murray for some of the alkaloid assays. Some financial support was provided by the Australian Lot Feeders Association through Meat and Livestock Australia.

\section{References}

Anon. (2003) 'Agricultural Standards Regulations 1997.' (Queensland Government: Brisbane) Available at http://www.legislation.qld.gov.au/ LEGISLTN/CURRENT/A/AgrStandR97.pdf [Verified 1 September 2009]

ANZFA (1999) 'Review of the maximum permitted concentrations of nonmetals in food.' (Australia New Zealand Food Authority: Canberra) Available at http://www.foodstandards.gov.au/_srcfiles/P158_FAR.pdf [Verified 1 September 2009]

ANZFA (2000) Variations to the Food Standards Code 1.4.1 Contaminants, Amendment 53 to the Code. Commonwealth of Australia Gazette 20 Dec. 2000.

Bakau BJK, Peacock AJ, Love RJ, Bryden WL (1988) Toxicity of ergots of Claviceps purpurea in growing pigs subjected to different ambient temperatures. Proceedings of the Nutrition Society of Australia 13, 136.

Berde B, Stürmer E (1978) Introduction to the pharmacology of ergot alkaloids and related compounds as a basis of their therapeutic application. In 'Ergot alkaloids and related compounds'. (Eds B Berde, HO Schild) pp. 1-28. (Springer Verlag: Berlin)

Blaney BJ, McKenzie RA, Walters JR, Taylor LF, Bewg WS, Ryley MJ, Maryam R (2000) Sorghum ergot associated with agalactia and feed refusal in pigs and dairy cattle. Australian Veterinary Journal 78, 102-107. doi: 10.1111/j.1751-0813.2000.tb10535.x

Blaney BJ, Kopinski JS, Murray S-A, McLennan SR, Moss RJ, Downing JG, Dingle JG (2001) Research on the toxicity of sorghum ergot and its alkaloids. In 'Proceedings from the 4th Australian sorghum conference'. (CD-ROM) (Range Media: Toowoomba)

Blaney BJ, Maryam R, Murray SA, Ryley MJ (2003) Alkaloids of the sorghum ergot pathogen (Claviceps africana): assay methods for grain and feed and variation between sclerotia/sphacelia. Australian Journal of Agricultural Research 54, 167-175. doi: 10.1071/AR02095

Blaney BJ, Chakraborty S, Murray S-A (2006) Alkaloid production by isolates of the sorghum ergot pathogen (Claviceps africana) from Australia and other countries. Australian Journal of Agricultural Research 57, 1023-1028. doi: 10.1071/AR05334

Bourke CA (2000) Recent outbreaks of ergot of rye poisoning in sheep and cattle have further clarified the historical confusion that surrounds this problem. Asian-Australasian Journal of Animal Science 13(Suppl.), 214.

Bourke CA (2003) Evidence that enforced sunlight exposure can cause hyperthermia in cattle ingesting low levels of ergot of rye (Claviceps purpurea), when air temperatures and humidity conditions are only moderate. Australian Veterinary Journal 81, 553-558. doi: 10.1111/ j.1751-0813.2003.tb12886.x

Browning R, Leite-Browning ML (1997) Effect of ergotamine and ergonovine on thermal regulation and cardiovascular function in cattle. Journal of Animal Science 75, 176-181.

Buchta M, Cvak L (1999) Ergot alkaloids and other metabolites of the genus Claviceps. In 'Ergot, the genus Claviceps. Vol. 6'. (Eds V Kren, L Cvak) pp. 173-200. (Harwood Academic Publishers: Amsterdam, The Netherlands)

Dignean MA, Schiefer HB, Blair R (1986) Effects of feeding ergotcontaminated grain to pregnant and nursing sows. Journal of Veterinary Medicine 33, 767-776.

EFSA (2005) Opinion of the scientific panel on contaminants in food chain on a request from the commission related to ergot as undesirable substance in animal feed. The EFSA Journal 225, 1-27. 
Frach K, Blaschke G (1998) Separation of ergot alkaloids and their epimers and determination in sclerotia by capillary electrophoresis. Journal of Chromatography. A 808, 247-252. doi: 10.1016/S00219673(98)00099-5

Franck B (1969) Structure and biosynthesis of the ergot pigments. Angewandte Chemie International Edition 8, 251-260. doi: 10.1002/ anie. 196902511

Grain Trade Australia (2009) 2009/10 grain standards. Available at http:// www.nacma.com.au/grain_specifications/sections_2_grains [Verified 1 September 2009]

Hill NS, Thompson FN, Stuedemann JA, Rottinghaus GW, Ju HJ, Dawe DL, Hiatt EE (2001) Ergot alkaloid transport across ruminant gastric tissues. Journal of Animal Science 79, 542-549.

Jang IH, van der Tol J, Bryden WL (1987) Ergotism in dairy cattle - effects of ingestion of ergots from Claviceps purpurea. Proceedings of the Nutrition Society of Australia 12, 169.

Jessep TM, Dent CHR, Kemp JB, Christie B, Ahrens PJ, Burgess LW, Bryden WL (1987) Bovine idiopathic hyperthermia. Australian Veterinary Journal 64, 353-354. doi: 10.1111/j.1751-0813.1987. tb06068.x

Kopinski JS, Blaney BJ, Downing JA, McVeigh JF, Murray S-A (2007) Feeding sorghum ergot (Claviceps africana) to sows before farrowing inhibits milk production. Australian Veterinary Journal 85, 169-176. doi: 10.1111/j.1751-0813.2007.00139.x

Kopinski JS, Blaney BJ, Downing JA (2008) Effect of 0.3\% sorghum ergot (Claviceps africana) in sow diets on plasma prolactin, lactation and piglet growth: regulatory implications. World Mycotoxin Journal 1, 475-482.

Mainka S, Danicke S, Bohme H, Ueberschar K-H, Liebert F (2007) On the composition of ergot and the effects of feeding two different ergot sources on piglets. Animal Feed Science and Technology 139, 52-68. doi: 10.1016/j.anifeedsci.2006.12.001

Müller C, Klaffke HS, Krauthause W, Wittkowski R (2006) Determination of ergot alkaloids in rye flour. Mycotoxin Research 22, 197-200. doi: 10.1007/BF02946741

Oresanya TF, Patience JF, Zijlstra RT, Beaulieu AD, Middleton DM, Blakley BR, Gillis DA (2003) Defining the tolerable level of ergot in the diet of weaned pigs. Canadian Journal of Animal Science 83, 493-500.

Peet RL, McCarthy MR, Barbetti MJ (1991) Hyperthermia and death in feedlot cattle associated with the ingestion of Claviceps purpurea. Australian Veterinary Journal 68, 121. doi: 10.1111/j.1751-0813. 1991.tb00777.x

Porter JK, Bacon CB, Plattner RD, Arrendale RF (1987) Ergot peptide alkaloid spectra of Claviceps-infected tall fescue, wheat and barley. Journal of Agricultural and Food Chemistry 35, 359-361. doi: 10.1021/jf00075a019
Ross AD, Bryden WL, Bakau W, Burgess LW (1989) Induction of heat stress in beef cattle by feeding the ergots of Claviceps purpurea. Australian Veterinary Journal 66, 247-249. doi: 10.1111/j.17510813.1989.tb13581.x

Rotter RG, Marquardt RR, Young JC (1985) Effect of ergot from different sources and of fractionated ergot on the performance of growing chicks. Canadian Journal of Animal Science 65, 953-961.

Schneider DJ, Miles CO, Garthwaite I, Van Halderen A, Wessels JC, Lategan HJ (1996) First report of field outbreaks of ergot-related toxicity in South Africa. The Onderstepoort Journal of Veterinary Research 63, 97-108.

Scott PM, Lawrence GA (1980) Analysis of ergot alkaloids in flour. Journal of Agricultural and Food Chemistry 28, 1258-1261. doi: 10.1021/ jf60232a050

Scott PM, Lombaert GA, Pellaers P, Bacler S, Lappi J (1992) Ergot alkaloids in grain foods sold in Canada. Journal of AOAC International 75, 773-779.

Smith DJ, Shappell NW (2002) Technical note: epimerisation of ergopeptide alkaloids in organic and aqueous solvents. Journal of Animal Science 80, 1616-1622.

Stoll A (1945) Uber Ergotamin. Helvetica Chimica Acta 28, 1283-1308. doi: $10.1002 /$ hlca.6602801182

Stoll A (1952) Recent investigations on ergot alkaloids. In 'Progress in the chemistry of organic natural products'. (Ed. L Zechmeister) pp. 114-174. (Springer-Verlag: Vienna)

Stuedemann JA, Hill NS, Thompson FN, Fayrer-Hosken RA, Hay WP, Dawe DL, Seman DH, Martin SA (1998) Urinary and biliary excretion of ergot alkaloids from steers that grazed endophyte-infected tall fescue. Journal of Animal Science 76, 2146-2154.

Whittemore CT, Miller JK (1977) Further studies concerning the toxicity of ingested ergot sclerotia (Claviceps purpurea) to young and growing pigs. Research in Veterinary Science 22, 146-150.

Young JC, Chen Z (1982) Variability in the content and composition of alkaloids found in Canadian ergot. III. Triticale and barley. Journal of Environmental Science and Health. Part. B, Pesticides, Food Contaminants, and Agricultural Wastes 17, 93-107. doi: 10.1080/ 03601238209372305

Manuscript received 26 February 2009, accepted 18 May 2009 